\title{
Inhibitive Effect of Dirithromycin on the Corrosion of Zinc in Tetraoxosulphate(VI) Acid Medium
}

\author{
EMEKA OGOKO ${ }^{1}$ and ABIMBOLA OGUNSIPE ${ }^{2 *}$ \\ ${ }^{1}$ Department of Chemistry, National Open University of Nigeria, Lagos, Nigeria \\ ${ }^{2}$ Department of Chemistry, Federal University of Petroleum Resources, Effurun, Nigeria \\ bolasipe@yahoo.com
}

Received 17 October 2014 / Accepted 8 November 2014

\begin{abstract}
The inhibitive effect by dirithromycin, an antibacterial drug, on the corrosion of zinc has been investigated using weight loss method. The results obtained indicate that clindamycin inhibits zinc corrosion in tetraoxosulphate $(\mathrm{VI})$ acid $(0.01$ to $0.04 \mathrm{M})$ media. The inhibition efficiency increased with increasing inhibitor's concentration. Kinetic, thermodynamic and adsorption parameters were determined and discussed. The uninhibited corrosion of zinc followed first order kinetics; while the presence of dirithromycin increased the enthalpy of activation, $\Delta \mathrm{H}^{*}$ and therefore made corrosion less probable. The calculated $\Delta \mathrm{G}^{\ddagger}$ values for the corrosion processes were positive, but increased in the presence of dirithromycin, suggesting that the activated complex was rather unstable. The adsorption of dirithromycin on zinc surface was exothermic, spontaneous and was best described by Langmuir adsorption isotherm. The calculated values of activation energies and free energies of adsorption indicate that the adsorption process supports the mechanism of physical absorption.
\end{abstract}

Keywords: Adsorption, Corrosion kinetics, Inhibition, Dirithromycin, Inhibition Efficiency, Activation thermodynamics

\section{Introduction}

Corrosion is the gradual degradation of materials, especially metals, by chemical reaction with their environment. Degradation implies deterioration of physical properties of the material which can be a weakening of the material due to a loss of cross-sectional area; it can be the shattering of a metal due to hydrogen embrittlement, or it can be the cracking of a polymer due to sunlight exposure. Metallic zinc is a metal with several industrial applications: it is used in the production of alloys and in galvanizing to protect steel structures and it is still present as a chemical additive in rubber and paints. Zinc is often destroyed by contact with aggressive media such as bases, acids and salt solutions. The treatment of zinc with acidic solutions cannot be completely avoided, as this is necessary for scale removal and cleaning of zinc surfaces. Consequently, corrosion prevention of zinc has become a subject of practical, industrial and economic significance ${ }^{1-3}$. Corrosion prevention 
can take a number of forms depending on the circumstances of the metal being corroded, and the familiar corrosion prevention techniques include: cathodic protection, coating, plating and corrosion inhibition, to mention but a few.

A corrosion inhibitor is a chemical compound that, when added to a liquid or gas, decreases the corrosion rates of a material, typically a metal or an alloy. A common mechanism for inhibiting corrosion involves formation of a coating, often a passivation layer, which prevents access of the corrosive substance to the metal.

The literature is robust on the study of corrosion inhibition of zinc in acidic solutions using organic compounds containing hetero atoms $(\mathrm{N}, \mathrm{O}, \mathrm{S}$, or $\mathrm{P})$ and centres for $\pi$-electrons in their aromatic or long carbon chain system.

The presence of $n$ - and $\pi$-electrons provides enhances the adsorption of inhibitors on the metal surfaces. Several eco-friendly inhibitors, which are extracts from naturally occurring plants proved very effective as metal corrosion inhibitors ${ }^{4-8}$. Recently, research on ecofriendly inhibitors has been extended to the use of drugs. However, the use of dirithromycin as corrosion inhibitor for zinc has not been reported in the literature. Dirithromycin (Figure 1) is a macrolide glycopeptide antibiotic; it is a 14-membered lactone ring macrolide and is the C9-oxazine derivative of erithromycylamine. Dirithromycin has been indicated in the treatment of mild-to-moderate infections caused by susceptible strains of microorganisms: acute bacterial exacerbations of chronic bronchitis, secondary bacterial infection of acute bronchitis, community-acquired pneumonia, pharyngitis/tonsillitis, and uncomplicated skin and skin structure infections ${ }^{9}$.

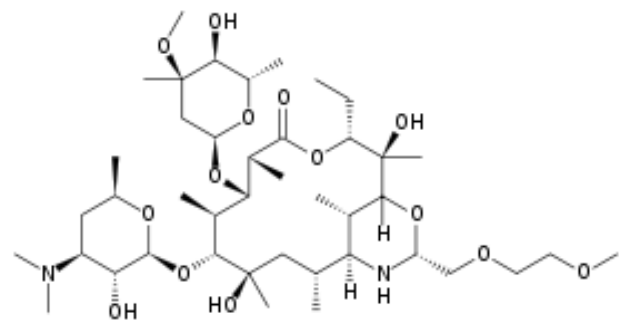

Figure 1. Structure of dirithromycin

The presence of many $n$ electron-carrying oxygen atoms in form of hetero atom and hydroxyl groups, as well as amino groups in the structure of should facilitate its adsorption onto zinc surface. In this work, we describe the corrosion inhibition tendencies of dirithromycin, as well as the effects of temperature and acid concentration on the inhibition process.

\section{Experimental}

Zinc sheets $\{(\mathrm{W} \%)$ : zinc (99.993), lead (0.001), iron (0.002), cadmium (0.001) and copper $(0.003)\}$ were purchased from the open market. Dirithromycin was supplied by Rufus Obi Pharmaceutical Company and used without further purification. Tetraoxoxulphate(VI) acid $\left(\mathrm{H}_{2} \mathrm{SO}_{4}\right)$ was purchased from SAARCHEM. Water was freshly distilled. Acetone, benzene and ethanol (Aldrich) were A.R. grades.

\section{Preparation of coupons}

Zinc specimens were mechanically pressed and cut into coupons of dimensions $5 \times 4 \mathrm{~cm}^{2}$, with a small hole of about $3 \mathrm{~mm}$ diameter just near one end of the specimen. Each coupon 
was polished by buffing and degreased in benzene and ethanol. They were then dipped in acetone and allowed to dry in air. The weight of each coupon was taken before being preserved in desiccators over silica gel beds.

\section{Weight loss experiments}

The zinc coupons were suspended in $200 \mathrm{~cm}^{3}$ solutions of $\mathrm{H}_{2} \mathrm{SO}_{4}$ contained in $250 \mathrm{~cm}^{3}$ beakers using a Pyrex glass hook. The weight loss experiments were carried out in various concentration of $\mathrm{H}_{2} \mathrm{SO}_{4}(0.01,0.02,0.03$ and $0.04 \mathrm{M})$ in the absence and presence of dirithromycin (different concentrations: $1 \times 10^{-4}$ to $5 \times 10^{-4} \mathrm{M}$ ) and at different temperatures $(303,313$ and $323 \mathrm{~K})$. The test solutions were maintained in a thermostated bath for $24 \mathrm{~h}$, after which each coupon was washed in $5 \%$ chromic acid containing $0.2 \% \mathrm{BaCO}_{3}{ }^{10}$, rinsed with distilled water followed by acetone and then dried in air. The coupons were then weighed again to determine the weight loss due to corrosion. From the weight loss experiment data, the following parameters were evaluated:

- Corrosion rates and order of reaction with respect to $\mathrm{H}_{2} \mathrm{SO}_{4}$

- Fractional surface coverage of dirithromycin on zinc surface $(\theta)$ and subsequently the equilibrium constant $\left(K_{a d s}^{o}\right)$, enthalpy $\left(\Delta K_{a d s}^{o}\right.$ ), entropy $\Delta S_{a d s}^{o}$ ) and free energy of adsorption ( $\Delta G_{a d s}^{o}$ ).

- $\quad$ Inhibition efficiency (IE\%) of dirithromycin

- Arrhenius parameters - Activation energy and pre-exponential factor $\left(E_{a}\right.$ and $A$ respectively)

- Thermodynamic functions (enthalpy, entropy and free energy) of activation $\left(\Delta \mathrm{H}^{\ddagger}, \Delta \mathrm{S}^{\ddagger}\right.$ and $\Delta \mathrm{G}^{\ddagger}$ respectively).

\section{Data Analyses}

\section{Corrosion rates ( $v_{\text {corr }}$ )}

Corrosion rates were calculated at (i) different $\mathrm{H}_{2} \mathrm{SO}_{4}$ concentrations, different dirithromycin concentrations and (iii) different temperatures; according to Equation 1:

$$
v_{\text {corr }}=\frac{w}{A . t}
$$

Where $W$ is the weight loss of zinc due to corrosion $(\mathrm{g}), A$, the cross-section area of the zinc coupon $\left(\mathrm{cm}^{2}\right)$ and $t$, the immersion time (h).

\section{Determination of reaction order}

The differential method was used in the determination of reaction order. This method involves measuring the initial corrosion rates at different $\mathrm{H}_{2} \mathrm{SO}_{4}$ concentrations.

The corrosion rate is represented as:

$$
v_{\text {corr }}=\mathrm{k}[\mathrm{Zn}]^{\mathrm{x}}\left[\mathrm{H}_{2} \mathrm{SO}_{4}\right]^{\mathrm{y}}
$$

Where $\mathrm{k}$ is the corrosion rate constant. $\mathrm{x}$ and $\mathrm{y}$ are the orders of the reaction with respect to zinc and $\mathrm{H}_{2} \mathrm{SO}_{4}$, respectively.

$\log v_{\text {corr }}$ values were then plotted against $\log \left[\mathrm{H}_{2} \mathrm{SO}_{4}\right]$ in accordance with Equation (3)

$$
\log v_{\text {corr }}=\log \mathrm{k}+\mathrm{x} \log [\mathrm{Zn}]+\mathrm{y} \log \left[\mathrm{H}_{2} \mathrm{SO}_{4}\right]
$$

Equation (3) can be rewritten as:

$$
\log v_{\text {corr }}=\mathrm{C}+\mathrm{y} \log \left[\mathrm{H}_{2} \mathrm{SO}_{4}\right]
$$




$$
\text { Where } \mathrm{C}=\log \mathrm{k}+\mathrm{x} \log [\mathrm{Zn}]\left(\text { or } \mathrm{C}=\log \mathrm{k}[\mathrm{Zn}]^{\mathrm{x}}\right. \text { ) }
$$

The slope of the plot is the order of reaction with respect to $\mathrm{H}_{2} \mathrm{SO}_{4}$.

\section{Adsorption parameters}

$\theta$, the fractional surface coverage was determined at different temperatures and dirithromycin concentrations according to Equation 6:

$$
\theta=1-\frac{w_{t}}{w_{U}}
$$

Where $W_{i}$ and $W_{u}$ are the inhibited and uninhibited weight losses due to corrosion. The Langmuir adsorption isotherm is described by the equation:

$$
\log \left(\frac{C}{\theta}\right)=\log C-\log K_{a d s}^{o}
$$

Where $\mathrm{C}$ is the concentration of the inhibitor, clindamycin, i.e. [Clin], and $K_{a d s}$, the equilibrium constant for the adsorption process. Plots of $\log \left(\frac{[\text { Clin] }}{\theta}\right)$ against $\log$ [Clin] at different $\mathrm{H}_{2} \mathrm{SO}_{4}$ concentrations and different temperatures gave straight lines with intercepts equal to $-\log K_{a d s}^{o}$ and slopes which should be ideally unity. Values of $K_{a d s}^{o}$ are then evaluated from the intercepts.

$K_{a d s}$ is related to the standard free energy of adsorption by Equation $(8 \mathrm{a})^{11}$ :

$$
K_{a d s}=\frac{1}{55.5} e^{\left[\frac{-\Delta G_{a d s}^{o}}{R T}\right]}
$$

Which can also be expressed as:

$$
\Delta \mathrm{G}_{\mathrm{ads}}=-\mathrm{RT} \ln \left(55.5 \mathrm{~K}_{\text {ads }}^{o}\right)
$$

55.5 is the value of the molar concentration $(\mathrm{M})$ of water in the solution ${ }^{12}$.

The adsorption of dirithromycin on zinc can be better explained using the enthalpy and entropy of adsorption, which can be calculated from the integrated Van't Hoff equation ${ }^{13,14}$ :

$$
\ln K_{a d s}=\frac{-\Delta H_{a d s}^{o}}{R T}+\frac{\Delta S_{a d s}^{o}}{R}+\ln \frac{1}{55.5}
$$

A plot of In $K_{a d s}$ against $\frac{1}{T}$ gave a straight line with slope equal to $\frac{-\Delta H_{a d s}^{o}}{R}$ and intercept equal to $\frac{\Delta S_{a d s}^{o}}{R}+\ln \frac{1}{55.5} \cdot \Delta \mathrm{G}_{\mathrm{ads}}$ values at different temperatures were calculated using the basic thermodynamic equation

$$
\Delta G_{a d s}^{o}=\Delta H_{a d s}^{o}+T \Delta S_{a d s}^{o}
$$

\section{Inhibition efficiency}

IE \% values were simply calculated using Equation (11):

$$
\text { IE } \%=100 \theta
$$

Where $\theta$ is the fractional surface coverage. IE\% values were shown to be dependent of the concentrations of dirithromycin and $\mathrm{H}_{2} \mathrm{SO}_{4}$, and on temperature. 


\section{Arrhenius parameters}

The effect of temperature on corrosion rates were analyzed using plots emanating from the Arrhenius-like equation:

$$
v_{\text {corr }}=A \cdot e \frac{-E_{a}}{R T}
$$

which could be rewritten as:

$$
\ln \left(\mathrm{v}_{\text {corr }}\right)=\ln \mathrm{A}-\frac{E_{a}}{R T}
$$

A plot of $\ln \left(v_{\text {corr }}\right)$ against $\frac{1}{T}$ gives a straight line, from which $E_{a}$ and the $A$ can both be determined from slope and intercept respectively.

\section{Thermodynamics}

The transition-state theory is an alternative to the Arrhenius theory, but with an advantage: it has been successful in calculating the standard enthalpy of activation $\left(\Delta H^{*}\right)$, the standard entropy of activation $\left(\Delta S^{\ddagger}\right)$ and the standard Gibbs energy of activation $\left(\Delta G^{*}\right)$ for a particular reaction if its rate constant has been experimentally determined. $\Delta H^{*}$ and $\Delta S^{*}$ for the formation of the activation complex were determining using Equation 13 (The transitionstate equation):

$$
v_{\text {corr }}=\frac{R T}{N h} e^{\left(\frac{\Delta S^{\ddagger}}{R}\right)} e^{\left(-\frac{\Delta H^{\ddagger}}{R T}\right)}
$$

which could be rewritten as:

$$
\ln \frac{v_{\text {corr }}}{T}=\ln \frac{R}{N h}+\frac{\Delta S^{\ddagger}}{R}-\frac{\Delta H^{\ddagger}}{R T}
$$

where $\mathrm{h}$ is Planck's constant and N, the Avogadro's number.

A plot of $\left(\ln \frac{V_{\text {corr }}}{T}\right)$ against $\frac{1}{T}$ gave a straight line with slope $-\frac{\Delta H^{\ddagger}}{R}$ and intercept $\left(\ln \frac{R}{N h}+\frac{\Delta S^{\ddagger}}{R}\right)$.

\section{Results and Discussion}

\section{Adsorption isotherm and adsorption parameters}

Adsorption is the process through which a substance, originally present in one phase, is removed from that phase by accumulation at the interface between that phase and a separate (solid) phase. The driving force for adsorption is the reduction in the interfacial tension between the fluid and the solid adsorbent as a result of the adsorption of the adsorbate on the surface of the solid.

The adsorption process is influenced by the chemical structures of organic compounds, charge distribution in the adsorbate molecules, the nature and surface charge of the metal and the type of corrodent ${ }^{15-17}$. The values of surface coverage for the different concentrations of dirithromycin were used to explain the best adsorption isotherm to describe the adsorption process. It was found that the isotherms for the zinc-dirithromycin system could be described by the classical Langmuir equation in the entire concentration and temperature 
ranges of the experimental data. Figure 2 shows the results of fitting using Langmuir isotherm equation. The linearity of the plots in Figure 2 implies that adsorption process is in conformity with the Langmuir isotherm. However, the slopes of the plots are not unity and this suggests the lack of perfect conformity with the isotherm. $K_{a d s}^{o}$ is a measure of how strongly the dirithromycin molecules are adhered onto zinc surface. As the temperature is increased, $K_{a d s}^{o}$ values become smaller, implying that high temperature shifts the adsorption-desorption equilibrium to favour desorption. However, $K_{a d s}^{o}$ values decrease with increasing $\mathrm{H}_{2} \mathrm{SO}_{4}$ concentration. The presence of the acid competes with dirithromycin for the zinc surface. Again, at a high acid concentration, a reaction between dirithromycin and the acid cannot be ruled out. $\Delta H_{a d s}^{o}$ and $\Delta S_{a d s}^{o}$ values in Table 1 are negative. Adsorption of dirithromycin leads to a decrease in the residual forces on zinc surface (as a result of the attractive forces between clindamycin molecules and zinc surface). This causes a decrease in the surface energy of the adsorbent, thereby making the process exothermic. Also, adsorption leads to a restriction of movement and decrease in disorderliness, i.e., lowering of entropy. There are marginal decreases in $\Delta H_{\text {ads }}^{o}$ and $\Delta S_{\text {ads }}^{o}$ values as the acid's concentration increases, implying that the adsorbent-adsorbate attraction reduces at high acid concentrations.

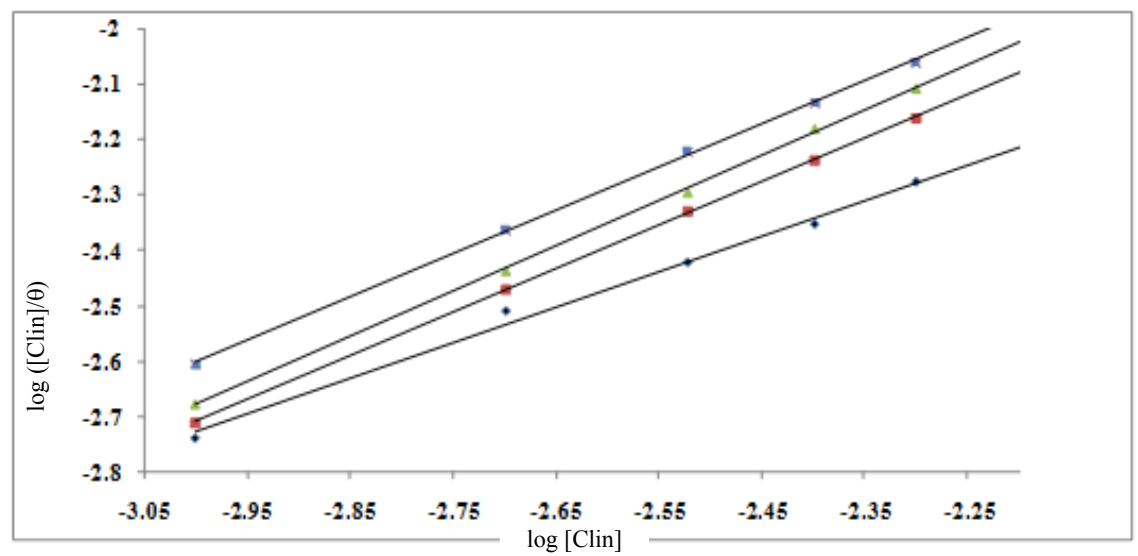

Figure 2. Langmuir isotherms for the adsorption of clindamycin on zinc surface at $303 \mathrm{~K}$ and different concentrations of $\mathrm{H}_{2} \mathrm{SO}_{4}$ : a, b, c, d = 0.01, 0.02, 0.03, $0.04 \mathrm{M}$ respectively.

The negative sign of $\Delta G_{a d s}^{o}$ (Table 1) indicates a spontaneous interaction between dirithromycin molecules and zinc surface ${ }^{18-20}$ and the stability of the adsorbed species on zinc surface. Values of $\Delta G_{a d s}^{o}$ are lower than $-15 \mathrm{~kJ} \mathrm{~mol}^{-1}$; usually values of $\Delta \mathrm{G}_{\text {ads }}$ around $20 \mathrm{~kJ} \mathrm{~mol}^{-1}$ or lower, are indicative of physisorption, while those higher than $-40 \mathrm{~kJ} \mathrm{~mol}^{-1}$ involve chemisorption ${ }^{21}$. Values of $-\Delta G_{a d s}^{o}$ (just like $K_{a d s}^{o}$ ) decrease with increase in temperature (Table 1), implying that desorption is favoured at high temperature. Table 1 shows that there is an agreement between the values of $\Delta G_{a d s}^{o}$ obtained via two different treatments, attesting to the validity of these results. 
Table 1. Adsorption parameters determined from Langmuir and Van't Hoff treatment of data

\begin{tabular}{lcccc}
\hline $\mathrm{T}, \mathrm{K}$ & $\Delta H_{a d s}^{o} / \mathrm{M}^{-1}$ & $\Delta H_{\text {ads }}^{o} / \mathrm{kJ} \mathrm{mol}^{-1}$ & $\Delta S_{\text {ads }}^{o} / \mathrm{J} \mathrm{mol}^{-1} \mathrm{~K}^{-1}$ & $* \Delta G_{a d s}^{o} / \mathrm{kJ} \mathrm{mol}^{-1}$ \\
\hline $0.01 \mathrm{M} \mathrm{H}_{2} \mathrm{SO}_{4}$ & & & $-14.81(-14.77)$ \\
303 & 6.33 & & & $-14.13(-14.10)$ \\
313 & 4.26 & -35.56 & -68.47 & $-13.44(-13.56)$ \\
323 & 2.64 & & & $-13.89(-13.13)$ \\
\hline $0.02 \mathrm{M} \mathrm{H}_{2} \mathrm{SO}_{4}$ & & & $-13.20(-12.93)$ \\
\hline 303 & 4.23 & & -68.21 & $-12.52(-12.30)$ \\
313 & 3.22 & -34.55 & & $-12.74(-12.15)$ \\
323 & 1.80 & & & $-12.05(-11.86)$ \\
\hline $0.03 \mathrm{M} \mathrm{H}_{2} \mathrm{SO}_{4}$ & & -68.19 & $-11.37(-11.25)$ \\
\hline 303 & 2.71 & & & $-11.73(-11.61)$ \\
313 & 2.02 & -33.52 & & $-11.10(-10.71)$ \\
323 & 1.18 & & -62.54 & $-10.48(-10.46)$ \\
\hline $0.04 \mathrm{M} \mathrm{H}_{2} \mathrm{SO}_{4}$ & & & \\
\hline 303 & 1.81 & & & \\
313 & 1.42 & -30.68 & & \\
323 & 1.05 & & & \\
\hline
\end{tabular}

${ }^{*}$ Values obtained using Equation 10; values in parentheses obtained using Equation 8

\section{Kinetic studies}

The kinetics of the corrosion process was studied in order to determine the apparent corrosion rate constant as well as the order of the reaction with respect to $\mathrm{H}_{2} \mathrm{SO}_{4}$, using the differential method. The differential method involves measuring the corrosion rates at different $\mathrm{H}_{2} \mathrm{SO}_{4}$ concentrations. The rate of the reaction, $v$, is represented as:

$$
v=\mathrm{k}^{\prime}\left[\mathrm{H}^{+}\right]^{\mathrm{n}}
$$

where $\mathrm{k}^{\prime}(=\mathrm{k}[\mathrm{Zn}])$ is the apparent rate constant, and $\mathrm{n}$ the order of the reaction with respect to $\mathrm{H}^{+}$. The corrosion rates were then plotted against $\mathrm{H}_{2} \mathrm{SO}_{4}$ concentration in accordance with Equation 15 (Figure 3),

$$
\log \mathrm{n}=\log \mathrm{k}^{\prime}+\mathrm{n} \log \left[\mathrm{H}^{+}\right]
$$

As shown in Figure 3, the corrosion reaction is first order $(\mathrm{n} \sim 1)$ with respect to $\mathrm{H}^{+}$.

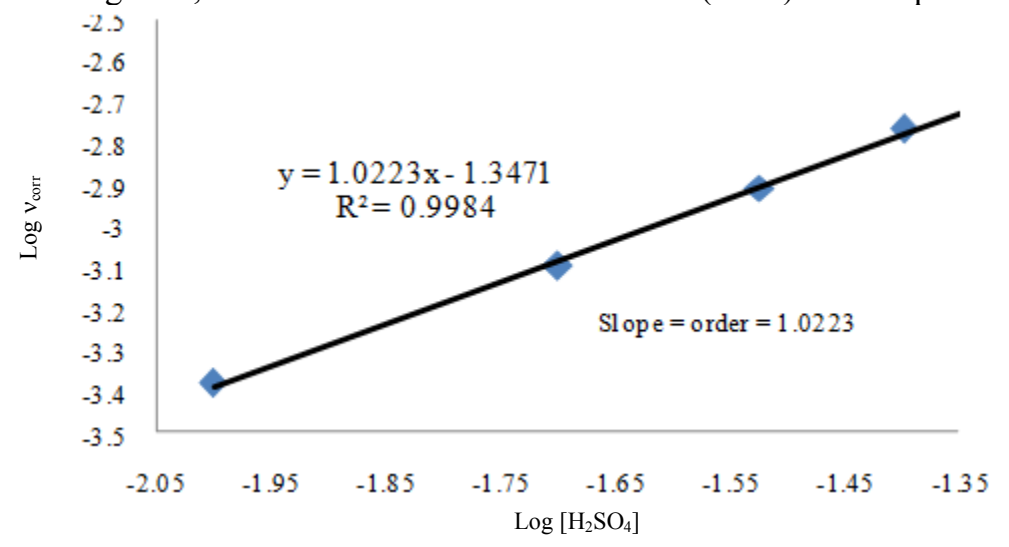

Figure 3. Determination of corrosion reaction order using the differential method 


\section{Effects of $\mathrm{H}_{2} \mathrm{SO}_{4}$ and dirithromycin concentrations on zinc corrosion}

Corrosion rate increases steadily with the acid's concentration at the three temperatures under which the study was made (Table 2). This observation is readily explained in terms of the collision theory of reaction rates. For corrosion to occur at all, the zinc atoms and $\mathrm{H}_{2} \mathrm{SO}_{4}$ molecules must at least collide. A basic requirement in a corrosion cell is that the anode (metal, zinc) and the cathode $\left(\mathrm{H}^{+}\right)$must be in electrical contact. If the concentration $\mathrm{H}_{2} \mathrm{SO}_{4}$ is higher, the chances of collision are greater, and an attendant increase in collision rate is expected.

Corrosion rate decreases at dirithromycin's (inhibitor) concentration increases (Table 2). A common mechanism for corrosion inhibition involves the formation of a coating, often a passivation layer, which prevents access of the corrosive substance $\left(\mathrm{H}_{2} \mathrm{SO}_{4}\right.$ in this case $)$ to the metal.

Table 2. Effects of dirithromycin concentration and temperature on the corrosion of zinc in $\mathrm{H}_{2} \mathrm{SO}_{4}$

\begin{tabular}{|c|c|c|c|c|c|c|c|c|}
\hline & \multicolumn{4}{|c|}{ Corrosion Rate, $\times 10^{-4} \mathrm{~g} \mathrm{~cm}^{-2} \mathrm{~h}^{-1}$} & \multicolumn{4}{|c|}{ Inhibition efficiency, $\%$} \\
\hline$\left[\mathrm{H}_{2} \mathrm{SO}_{4}\right]$ & 0.01 & 0.02 & 0.03 & 0.04 & 0.01 & 0.02 & 0.03 & 0.04 \\
\hline \multicolumn{9}{|l|}{ [Diri] (M); $303 \mathrm{~K}$} \\
\hline 0 & 4.13 & 7.98 & 12.4 & 17.1 & 0 & 0 & 0 & 0 \\
\hline 0.001 & 1.87 & 3.87 & 6.55 & 10.2 & 54.7 & 51.5 & 47.5 & 40.4 \\
\hline 0.002 & 1.47 & 3.27 & 5.65 & 9.21 & 64.5 & 59.0 & 54.4 & 46.1 \\
\hline 0.003 & 0.85 & 2.85 & 5.09 & 8.56 & 79.4 & 64.2 & 59.0 & 49.9 \\
\hline 0.004 & 0.42 & 2.47 & 4.90 & 7.81 & 89.7 & 69.1 & 60.5 & 54.3 \\
\hline 0.005 & 0.22 & 2.20 & 4.44 & 7.27 & 94.7 & 72.4 & 64.2 & 57.5 \\
\hline \multicolumn{9}{|l|}{ [Diri] (M); $313 \mathrm{~K}$} \\
\hline 0 & 7.82 & 14.7 & 21.3 & 28.8 & 0 & 0 & 0 & 0 \\
\hline 0.001 & 4.39 & 8.61 & 13.0 & 18.1 & 43.9 & 41.4 & 39.1 & 37.2 \\
\hline 0.002 & 3.80 & 7.83 & 12.3 & 17.1 & 51.4 & 46.7 & 42.2 & 40.7 \\
\hline 0.003 & 3.21 & 6.91 & 11.1 & 16.0 & 59.0 & 53.0 & 47.8 & 44.3 \\
\hline 0.004 & 2.80 & 6.21 & 10.4 & 14.7 & 64.2 & 57.7 & 51.4 & 49.8 \\
\hline 0.005 & 2.30 & 4.90 & 9.00 & 14.2 & 70.6 & 66.7 & 57.8 & 50.6 \\
\hline \multicolumn{9}{|l|}{ [Diri] $(\mathrm{M}) ; 323 \mathrm{~K}$} \\
\hline 0 & 15.8 & 29.7 & 43.7 & 58.1 & 0 & 0 & 0 & 0 \\
\hline 0.001 & 9.50 & 18.2 & 27.7 & 38.8 & 39.8 & 38.5 & 36.7 & 33.3 \\
\hline 0.002 & 8.72 & 17.5 & 26.7 & 36.6 & 44.7 & 40.9 & 38.9 & 37.0 \\
\hline 0.003 & 7.82 & 16.2 & 25.8 & 35.4 & 50.4 & 45.3 & 40.9 & 39.0 \\
\hline 0.004 & 6.65 & 14.8 & 24.3 & 33.3 & 57.9 & 50.3 & 44.4 & 42.7 \\
\hline 0.005 & 6.04 & 12.9 & 21.9 & 32.0 & 61.7 & 56.6 & 49.9 & 44.9 \\
\hline
\end{tabular}

However, Inhibition efficiency (I.E) increases on increasing the dirithromycin's concentration (Figure 4). Inhibition efficiency (I.E) was observed to decrease as the corrodent's concentration increases. At high $\mathrm{H}^{+}$concentrations, the corrosion rate is so high that the effectiveness of the inhibitor will be minimized. Again at a high concentration, $\mathrm{H}_{2} \mathrm{SO}_{4}$ probably attacks dirithromycin, thereby reducing the effective concentration of the inhibitor.

The effect of temperature on the acid-induced corrosion of a metal is rather complex; processes such as metal etching, alteration of the inhibitor adsorption-desorption equilibrium and the reaction (e.g., decomposition) of the inhibitor itself ${ }^{22}$, are bound to take place. 


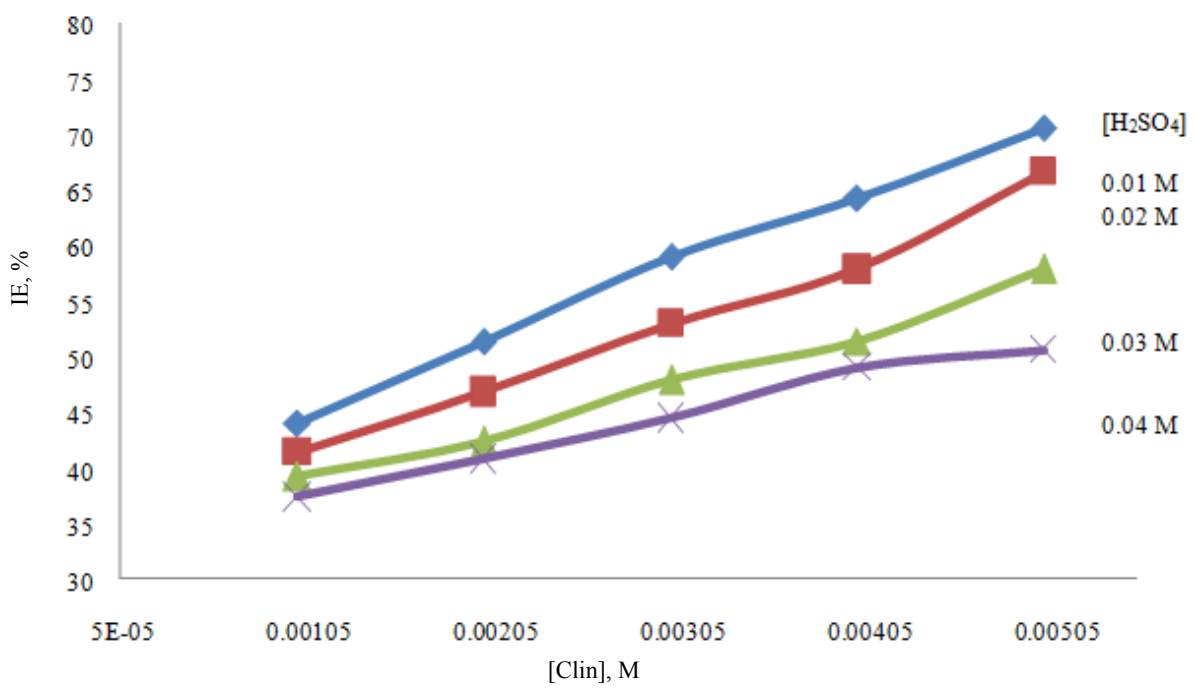

Figure 4a. Dependence of inhibition efficiency (I.E) on clindamycin and $\mathrm{H}_{2} \mathrm{SO}_{4}$ concentrations at $313 \mathrm{~K}$

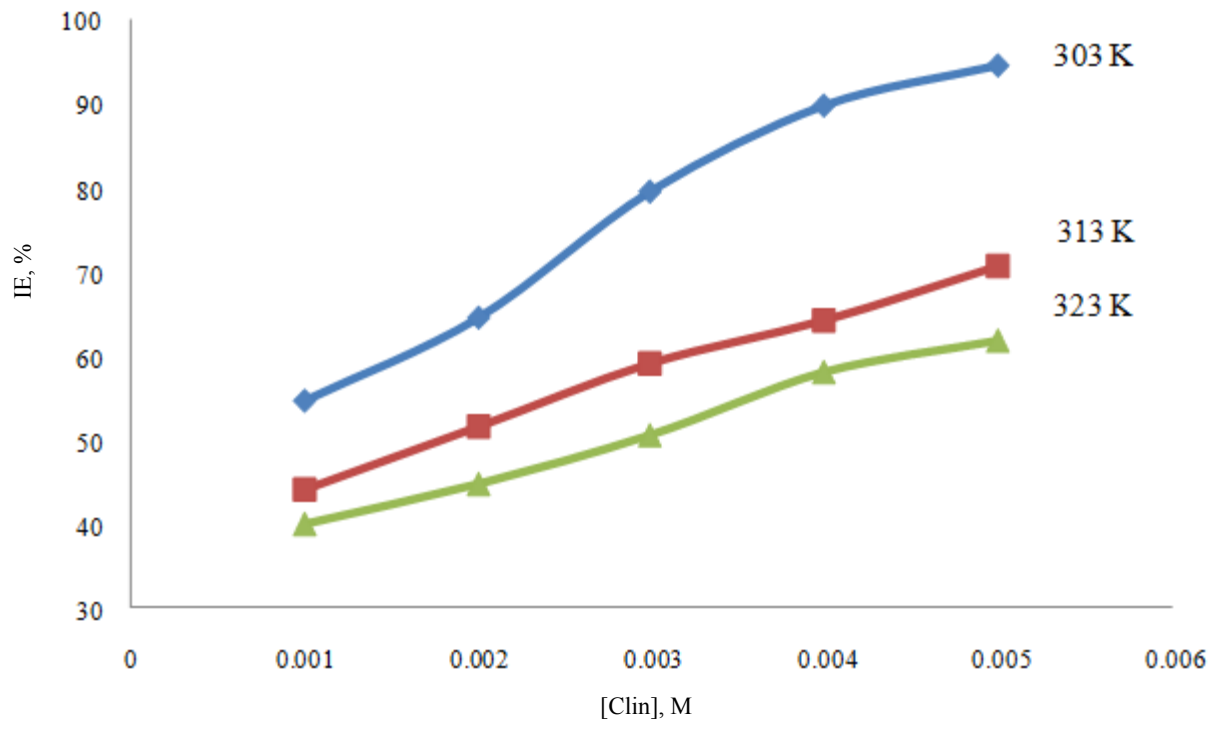

Figure 4b. Dependence of inhibition efficiency on temperature $\left(\mathrm{H}_{2} \mathrm{SO}_{4}\right.$ concentration $\left.=0.01 \mathrm{M}\right)$

\section{Effects of temperature}

For corrosion to take place, zinc atoms and $\mathrm{H}^{+}$ions must possess energies equal to or higher than the activation energy $E_{a}$. At low temperature, only a few molecules have sufficient energy - the reaction will proceed, but at a slow rate. At higher temperate, more molecules are able to surpass the energy barrier: the reaction proceeds at a faster rate.

At a particular $\mathrm{H}_{2} \mathrm{SO}_{4}$ concentration, corrosion rate increases with temperature (Table 2). Every reaction has an energy barrier. The fact that a reaction increases with increasing 
temperature suggests that only molecules with sufficient energy are able to react. In the presence of dirithromycin (inhibitor), inhibition efficiency (I.E) decreases as the temperature is increased. An increase in temperature might stimulate larger metal surface kinetic energy, which leads to a decrease in the quantity of dirithromycin adsorbed. Adsorption is an exothermic process ${ }^{23}$ and one would expect therefore that an increase in temperature should cause a decrease in adsorption. Also, the adsorption-desorption process is a dynamic equilibrium, favouring desorption at high temperatures ${ }^{24}$, and as a result of dirithromycin desorption, a greater surface area of zinc is exposed to the aggressive acid environment, resulting in an increase in corrosion rate and an attendant reduction in I.E. The decreased adsorption at high temperature indicates that dirithromycin is physically adsorbed onto zinc surface ${ }^{17,25}$.

\section{Arrhenius plots}

The dependence of the corrosion rate on temperature can be expressed by the Arrhenius equation and transition state equation. The Arrhenius equation (Equation 12) predicts that corrosion rate increases with the temperature and Ea and A may vary with temperature. Figure 5 shows Arrhenius plots for the temperature dependence of zinc corrosion rates in the absence and presence of dirithromycin. The calculated activation energies (Ea) and preexponential factors (A) at different concentrations of dirithromycin are listed in Table 3.

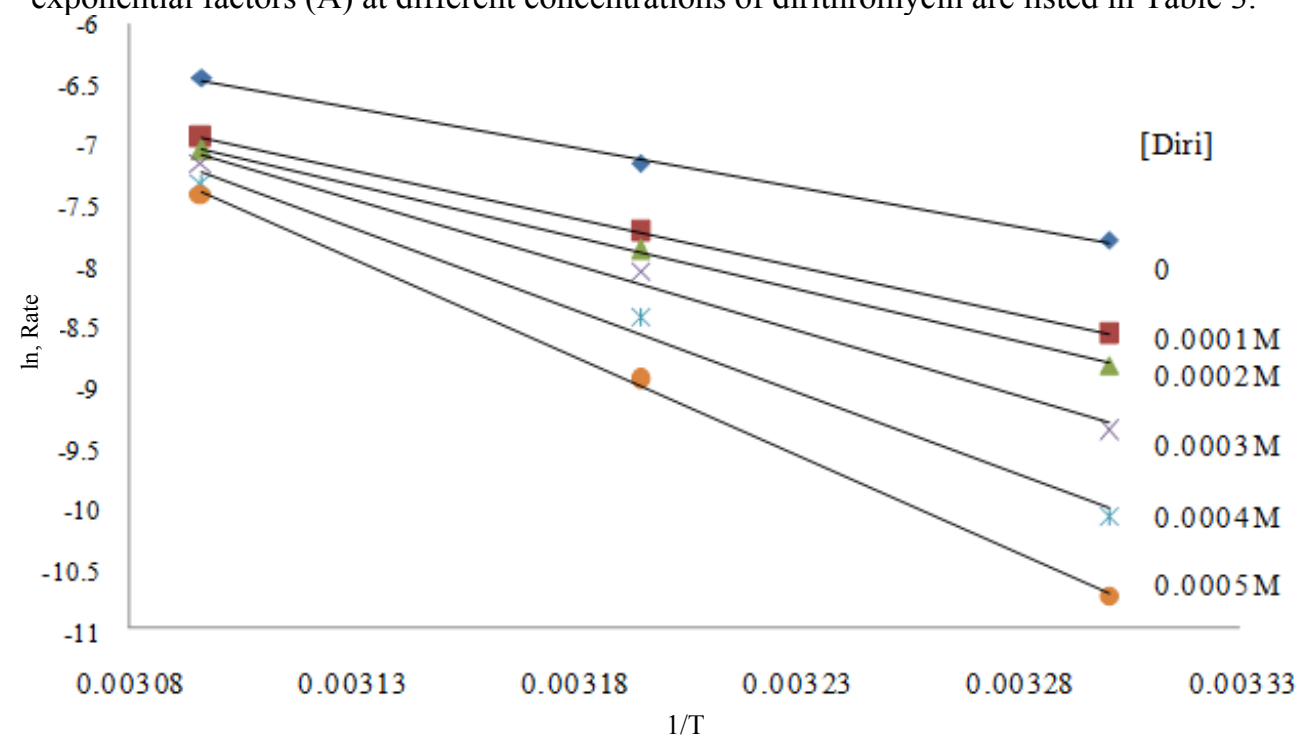

Figure 5. Arrhenius plots for the corrosion of zinc in $\mathrm{H}_{2} \mathrm{SO}_{4}$ - effect of clindamycin inhibitor

Both $\mathrm{E}_{\mathrm{a}}$ and $\mathrm{A}$ increase as the concentration of dirithromycin is increased. The dirithromycin concentration-dependence of $\mathrm{E}_{\mathrm{a}}$ may be explained thus: the adsorbed dirithromycin molecules modify the mechanism of the corrosion process by presenting an additional energy barrier for the process to take place ${ }^{26,27}$. At the molecular level, the $\mathrm{H}^{+}$ions do not have easy (direct) contact with the metal surface as the dirithromycin concentration is increased.

\section{Activation thermodynamics}

The activation parameters of the corrosion process in the presence of varying concentrations of dirithromycin are listed in Table 3. The activation enthalpy $\left(\Delta \mathrm{H}^{*}\right)$ is the least amount of energy required for a reaction to take place. It is the heat energy needed to raise the reactants to the 
transition state $\Delta \mathrm{H}^{*}$ increases (becomes more positive) as dirithromycin concentration is increased. As explained above, the introduction of dirithromycin presents additional energy barrier for the process. The increase in $\Delta \mathrm{H}^{*}$ reduces the tendency of $\Delta \mathrm{G}^{*}$ to be negative $\left(\Delta \mathrm{G}^{*}=\right.$ $\left.\Delta \mathrm{H}^{*}-\mathrm{T} \Delta \mathrm{S}^{*}\right)$. So as expected, the presence of dirithromycin increases $\Delta \mathrm{H}^{*}$, and therefore makes $\Delta \mathrm{G}^{\ddagger}$ less negative (corrosion becomes less likely). $\Delta \mathrm{H}^{\ddagger}$ varies with dirithromycin concentration in the same way as $E_{a}$ (Figure 6). This observation permits us to verify the known thermodynamic relation between the two quantities for reactions in solution ${ }^{28}$ :

$$
\mathrm{E}_{\mathrm{a}}-\Delta \mathrm{H}^{*}=\mathrm{RT}
$$

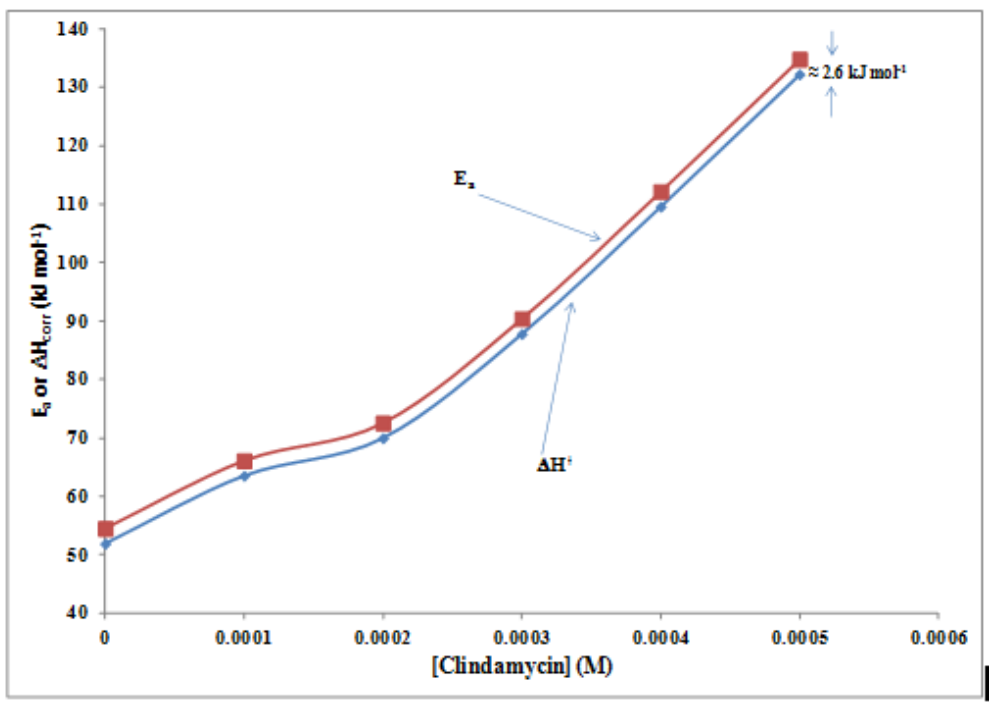

Figure 6. Variation of $\mathrm{E}_{\mathrm{a}}$ and $\Delta \mathrm{H}^{\dagger}$ with clindamycin concentration; relationship between $\mathrm{E}_{\mathrm{a}}$ and $\Delta \mathrm{H}^{\ddagger}$

Table 3. Activation parameters for the corrosion of zinc in $0.01 \mathrm{M} \mathrm{H}_{2} \mathrm{SO}_{4}$; effect of dirithromycin

\begin{tabular}{ccccccc}
\hline$[$ Diri] $/ \mathrm{M}$ & $\begin{array}{c}\mathrm{E}_{\mathrm{a}} \\
/ \mathrm{kJ} \mathrm{mol}^{-1}\end{array}$ & $\begin{array}{c}\mathrm{A} \\
/ \mathrm{g} \mathrm{cm}^{-2} \mathrm{hr}^{-1}\end{array}$ & $\begin{array}{c}\Delta \mathrm{H}^{\ddagger} \\
\mathrm{kJ} \mathrm{mol}^{-1}\end{array}$ & $\begin{array}{c}\Delta \mathrm{S}^{\ddagger} \\
/ \mathrm{J} \mathrm{K}^{-1} \mathrm{~mol}^{-1}\end{array}$ & $\begin{array}{c}\mathrm{E}_{\mathrm{a}}-\Delta \mathrm{H}^{\ddagger} \\
/ \mathrm{kJ} \mathrm{mol}^{-1}\end{array}$ & $\begin{array}{c}\Delta \mathrm{G}^{\ddagger} \text { at } 303 \mathrm{~K} \\
/ \mathrm{kJ} \mathrm{mol}^{-1}\end{array}$ \\
\hline 0 & 54.5 & $1.01 \times 10^{6}$ & 51.9 & -82.0 & 2.598 & +76.8 \\
0.0001 & 66.1 & $4.66 \times 10^{7}$ & 63.5 & -50.1 & 2.597 & +78.7 \\
0.0002 & 72.5 & $4.76 \times 10^{8}$ & 70.0 & -30.8 & 2.593 & +79.3 \\
0.0003 & 90.4 & $3.47 \times 10^{11}$ & 87.8 & 24.0 & 2.588 & +80.5 \\
0.0004 & 112 & $9.98 \times 10^{14}$ & 109 & 90.2 & 2.587 & +82.3 \\
0.0005 & 134 & $3.94 \times 10^{18}$ & 132 & 159 & 2.595 & +84.0 \\
\hline
\end{tabular}

At 303,313 and $323 \mathrm{~K}$, the respective values of RT are $2.519,2.602$ and $2.685 \mathrm{~kJ} \mathrm{~mol}^{-1}$, with an average of $2.602 \mathrm{~J} \mathrm{~mol}^{-1}$. The values of $\mathrm{E}_{\mathrm{a}}-\Delta \mathrm{H}^{*}$ at the different dirithromycin concentrations are listed in Table 3; these values are similar to $2.602 \mathrm{~J} \mathrm{~mol}^{-1}$ (within experimental error). This result shows that the inhibitor acted equally on $\mathrm{E}_{\mathrm{a}}$ and $\Delta \mathrm{H}^{\star}$ (Figure 6). The difference between Arrhenius activation energy $E_{a}$ and the activation enthalpy $\Delta H^{*}$ are quite small and numerically close to the accuracy attained in most experiments $(\mathrm{RT}=2.5$ $\mathrm{kJ} / \mathrm{mol}$ at $298.15 \mathrm{~K}$ ). These two energies are therefore frequently used interchangeably in the literature to define the activation barrier of a reaction. 
The activation entropy deals with how the energy within the molecule must be redistributed for the reaction to occur. For the uninhibited reaction, $\Delta \mathrm{S}^{*}$ is negative (Table 3 ), suggesting that the activated complex in the rate-determining step represents an association rather than a dissociation step, which in turn implies that a increase in order takes place on going from reactants to the activated complex. It is logical to think that the presence of dirithroamycin molecules somewhat impedes the approach of the acid molecules unto the metal surface (thereby increasing disorder) in forming the activated complex. In Table 3, the value of $\Delta \mathrm{S}^{\ddagger}$ increases (becomes more positive) with dirithromycin concentration, attaining $159 \mathrm{~J} \mathrm{~mol}^{-1} \mathrm{~K}^{-1}$ when [dirithromycin] $=0.0005 \mathrm{M}$.

The calculated $\Delta \mathrm{G}^{*}$ values for the corrosion processes (Table 3) are positive, but increased in the presence of dirithromycin, suggesting that the activated complex is rather unstable, and the likelihood of its formation decreased marginally in the presence of dirithromycin $(0.0001-0.0005 \mathrm{M})$. However, there are no marked changes in $\Delta \mathrm{G}^{*}$ values as the temperature was increased to 313 and $323 \mathrm{~K}$ respectively.

\section{Conclusion}

In conclusion, this work has shown that dirithromycin, an antibacterial drug, suffices well for the inhibition of zinc corrosion in acid medim. The isotherms for the zinc-dirithromycin system could be described by the classical Langmuir equation in the entire concentration and temperature ranges of the experimental data; and decreased adsorption at high temperature indicates that dirithromycin is physically adsorbed onto zinc surface. The corrosion reaction was first order $(\mathrm{n} \sim 1)$ with respect to $\mathrm{H}^{+}$, and was significantly inhibited by dirithromycin. The presence of dirithromycin increased $\Delta \mathrm{H}^{\ddagger}$, and therefore made $\Delta \mathrm{G}^{\ddagger}$ less negative (corrosion becomes less likely). $\Delta \mathrm{H}^{*}$ varied with dirithromycin concentration in the same way as $\mathrm{E}_{\mathrm{a}}$. The calculated $\Delta \mathrm{G}^{\ddagger}$ values for the corrosion processes were positive, but increased in the presence of dirithromycin, suggesting that the activated complex was rather unstable.

\section{References}

1. Ogoko E C, Odoemelam S A, Ita B I and Eddy N O Portugaliae Electrochimica Acta., 2009, 27(6), 713-724; DOI:10.4152/pea.200906713

2. Odoemelam S A, Ogoko E C, Ita B I and Eddy N O Portugaliae Electrochimica Acta, 2009, 27(1), 57-68; DOI:10.4152/pea.200901057

3. Eddy N O, Odoemelam S A, Ogoko E C and Ita B I Portugaliae Electrochimica Acta, 2010, 28(2), 73-85; DOI:10.4152/pea.201002073

4. Abiola O K, Oforka N C, Ebenso E E and Nwinuka N M, Anti-Corrosion Methods Mater., 2007, 54(4), 219-224; DOI:10.1108/00035590710762357

5. Arora P, Kumar S, Sharma M K and Mathur S P, J Chem., 2007, 4(4), 450-456; DOI:10.1155/2007/487820

6. Abiola O K, Aliyu A O C, Phillips A A and Ogunsipe A O, J Mater Environ Sci., 2013, 4(3), 370-373.

7. James A O, Oforka N C and Abiola O K, Bull Electrochem., 2006, 22(3), 111-116.

8. Rajappa S K, Venkatesha T V and Praveen B M, Bull Mater Sci., 2008, 31(1), 37-41; DOI:10.1007/s12034-008-0007-3

9. Brogden R N and Peters D H, Drugs, 1994, 48(4), 599-616.

10. Stroud E G, J Appl Chem., 1951, 1(3), 93-95.

11. Schorr M and Yahalom J, Corros Sci., 1972, 12(11), 867-868; DOI:10.1016/S0010938X(72)80015-5 
12. Flis $\mathrm{J}$ and Zakroczymski T, J Electrochem Soc., 1996, 143(8), 2458-2464; DOI:10.1149/1.1837031

13. Ebenso E E and Obot I B, Int J Electrochem Sci., 2010, 5, 2012-2035.

14. Musa A Y, Khadum A A H, Mohamad A B, Daud A R, Takriff M S and Kamarudin S K, Corros Sci., 2009, 51(10), 2393-2399; DOI:10.1016/j.corsci.2009.06.024

15. Zhang Q B and Hua Y X, Electrochimica Acta, 2009, 54(6), 1881-1887; DOI:10.1016/j.electacta.2008.10.025

16. Saleh M R and Din A M S E, Corros Sci., 1972, 12(9), 689-697; DOI:10.1016/S0010-938X(72)91188-2

17. Maayta A K and Al-Rawashdeh N A F, Corros Sci., 2004, 46(5), 1129-1140; DOI:10.1016/j.corsci.2003.09.009

18. Gomma G K and Wahdan M H, Indian J Chem Technol., 1995, 2, 107-110.

19. Keles H, Keles M, Dehri I and Serindag O, Colloids Surf A: Physicochem Engg Aspect.,, 2008, 320(1-3), 138-145; DOI:10.1016/j.colsurfa.2008.01.040

20. Fouda A S, Heakal F E and Radwan M S, J Appl Electrochem, 2009, 39(3), 391-402; DOI:10.1007/s10800-008-9684-2

21. Umoren S A, Obot I B, Ebenso E E, Okafor P C, Ogbobe O and Oguzie E E, AntiCorros Meth Mater., 2006, 53(5), 277-282; DOI:10.1108/00035590610692545

22. Bentiss F, Lebrini M, Vezin H, Chai F, Traisnel M and Lagrene M, Corr Sci., 2005, 51(9), 2165-2173; DOI:10.1016/j.corsci.2009.05.049

23. Bartell F E, Thomas T L and Ying F, J Phys Chem., 1951, 55, 1456-1462.

24. Shukla S K and Quraishi M A, Corr Sci., 2010, 52(2), 314-321; DOI:10.1016/j.corsci.2009.09.017

25. Zarrok H, Zarrouk A, Hammouti B, Salghi R, Jama C and Bentiss F, Corr Sci., 2012, 64, 243-252; DOI:10.1016/j.corsci.2012.07.018

26. Zarrouk A, Hammouti B, Zarrok H, Al-Deyab S S and Messali M, Int J Electrochem Sci., 2011, 6(12), 6261-6274.

27. Al-Luaibi Salah S, Azad S and Taobi Abdel-Amir H, J Mater Environ Sci., 2011, 2(2), 148-155.

28. Stern $\mathrm{M}$ and Geary A L, J Electrochem Soc., 1957, 104(1), 56-63; DOI:10.1149/1.2428496 